\title{
ARE RUSSELLIAN INDEXICALS ELIMINABLE?
}

\author{
¿SON LOS INDEXICALES RUSSELLIANOS ELIMINABLES?
}

\author{
Sebastián Sanhueza ${ }^{1}$ \\ Universidad de Concepción
}

\begin{abstract}
It is widely thought that, in his later work $A n$ Inquiry into Meaning and Truth, Bertrand Russell argued that our natural languages could in principle do away with indexicals. This brief piece, by contrast, aims to show that, instead of suggesting the potential eliminability of such expressions, Russell outlined a semantic account of indexicals according to which such expressions fundamentally depend on the perspectival way in which they refer to worldly items. If correct, this proposal would not only show that, in Russell's later work, the meaning of expressions like indexicals is not exhaustively determined by the items they refer to: it would also show that Russell did not mean to eliminate indexicals from our natural languages at all.
\end{abstract}

Keywords: Indexicals; Bertrand Russell; Acquaintance; Causal Chains; Names.
Recibido: 22.04.2019 - Aceptado: 05.12.2019

\section{RESUMEN}

Comúnmente se piensa que, en su trabajo tardío Una Investigación sobre el Significado y la Verdad, Bertrand Russell sostuvo que nuestros lenguajes naturales podrían en principio precindir de expresiones indexicales. Este breve artículo, sin embargo, busca demostrar que, en lugar de sugerir la posible eliminación de tales expresiones, Russell delineó una teoría semántica de los indexicales según la cual tales expresiones fundamentalmente dependen del modo perspectival en el cual refieren aítems del mundo. Si es correcta, esta propuesta no sólo demostraría que, en el trabajo tardío de Russell, el significado de expresiones tales como los indexicales no es exhaustivamente determinado por los ítems a los cuales ellas refieren, sino que también demostraría que Russell de ninguna manera buscó eliminar los indexicales de nuestros lenguajes naturales.

Palabras clave: Indexicales; Bertrand Russell; Familiaridad; Cadenas Causales; Nombre.

${ }^{1}$ ssanhue@gmail.com 


\section{INTRODUCTION}

The meaning of indexical expressions-e.g. 'I', 'this', 'here', 'now', among others-varies from context to context: I may now utter 'This is red' to pick out a pack of biscuits, and then, to pick out a red car passing by. Bertrand Russell posed the following questions regarding this kind of expressions: 'Is there, then, any need for these words at all? Or can everything be said without them?' (Russell 1962, 103) After a brief discussion, he concludes that indexical expressions-or, as he calls them, egocentric particulars-'are not needed in any part of the description of the world, whether physical or psychological' (Russell 1962, 108). This claim naturally suggests that, for Russell, it is possible to imagine a language where everything we express in actual natural languages-e.g. English or Spanish-with the help of indexical terms, could be expressed without them. If correct, a Russellian account of indexicals would show that such languages could dispense with such context-dependent terms (cf. Soles 1981, 32; Kaplan 1989, 558). In other words, Russell apparently suggests that our natural languages could do away with indexicals or that indexicals are eliminable. The conclusion is of course unappealing and Russell's account has accordingly been committed to the basement of bad philosophical ideas.

I do not believe that the previous reading is compulsory, though. This brief piece aims to show that Russell does not argue for the eliminability, either potential or practical, of indexicals. Although a Russellian approach to semantics is often characterized as fixing the meaning of a given category of expressions in terms of the worldly items such expressions refer to, ${ }^{2}$ Russell's semantic account of indexicals is clearly more sophisticated than that: for, when it comes to specify their meaning, Russell shows great sensitivity not only to the objects such expressions refer to, but also, more importantly, to the way in which the relevant terms refer to worldly items. More specifically, he outlines a semantic account of indexicals that takes into account the perspectival way in which indexicals refer to worldly items. True: he does suggest that a language that exclusively described the world of physics and biology, has no need for indexicals. However, this claim does not entail that language-users could potentially dispense with using such expressions: instead, it illustrates that the meaning of indexicals could not be specified by

${ }^{2}$ For further discussion of the principle behind this characterization, cf. (Russell 1918, 1956a; Bostock 2012; Martin 2015). 
merely describing the worldly items such expressions refer to. To the extent that their usage involves a key perspectival-and hence, subjective-component, indexicals are the kind of expression the meaning of which could not be fully expressed in a description of a fully objective-that is, perspectiveless-world. In this sense, and in this sense alone, we could eliminate indexicals from a language intended to describe the natural world. But as long as there be finite language-users - that is, language-users occupying a particular vantage point on the world they inhabit-indexicals could not, either in theory or in practice, be eliminated from their language.

The present task will be divided into three parts. To begin with, I briefly address two important preliminary issues: on the one hand, what Russell takes an account of indexicals to account for; and, on the other, what problem he takes such expressions to pose. Secondly, I go on to outline his general stance on indexicals: I outline how, instead of dispensing with such terms, Russell actually strived to describe the distinctively causal way in which indexicals express things about the world. Thirdly, I explain how Russell's comments about the apparent dispensability of indexicals could be accommodated within the foregoing causal story. While my line of reasoning by no means constitutes a definitive case on behalf of Russell's account, I expect it to bring it back from the aforementioned basement.

\section{WORD-USAGE AND THE PROBLEM OF MISBEHAVIOR}

As previously mentioned, this introductory section briefly addresses two questions. The first one is what the proper explanandum of Russell's account of indexicals is. While the grammatical category of indexical expressionsthat is, terms like 'this', 'that', etc.-may be the most obvious candidate, Russell seems to have a subtly different subject-matter in mind. For his account does not primarily concern a given class of grammatical items, but, more specifically, the way such terms are used when performing deictic identifications. Indexical terms are expressions of natural and artificial languages: they are available to be used by speakers or learners of those languagesthat is, they are particular items possessing certain definite properties, depending on the medium of communication. Deictic identification is, in turn, a mental or cognitive act by means of which a subject relates to her surroundings. While the concept of an indexical term is a grammatical one, that of deictic identification is a psychological or cognitive one. ${ }^{3}$ And even though

3 The present distinction mirrors the more familiar dichotomy between demonstrative terms and demonstrative identification. For the distinction between a linguistic term and its use, cf. (Russell 1962, 24). 
Russell himself does not make this distinction entirely explicit, the problem of indexicals he identifies as well as the account he accordingly provides, reveal that his main concern is not a category of grammatical terms like 'this' and 'that', but the use language-users make of those expressions. ${ }^{4}$

As for the question what problem Russell ascribes to indexicals, I term it here the Problem of Misbehavior. The problem is partially motivated by Russell's famous Principle of Acquaintance-or (PA), for short: that is, the claim that our understanding of the meaning of a simple, non-logical linguistic expression consists in becoming acquainted with the worldly item such an expression picks up on (cf. Russell 1956, 194; Sainsbury 1979, 26-41). ${ }^{5}$ Russell compares the way in which speakers use indexicals and other linguistic categories-specifically, names and descriptions. According to him, names tend to be used with a fixed meaning over time: once a name refers to something, it will refer to the same thing or have the same meaning over time. On the basis of this usage, the meaning of a given name may be modeled in accordance with (PA): for example, the meaning of the name 'Helen' is determined by the person that name actually refers to. Likewise, definite descriptions may be taken to refer to all the items fulfilling the conditions embraced by them: accordingly, their meaning is constituted by the items or scenarios that satisfy the relevant description. That said, indexicals are problematic because their use seems to involve contradictory traits. Per (PA), indexicals mean different things on different contexts: 'this' picks up on different items almost every time I use it-now a cup, then a laptop, and so on. But, at the same time, our usage of indexicals is not arbitrary either. Although Russell does not elaborate on this point, it may be expressed as follows: the non-arbitrary use of indexicals-or again, the non-arbitrary process of learning how to use them across different languages-suggests that an indexical term has a meaning that fixes its conditions of correct and incorrect usage.

Focusing on how the expression 'this' is used, Russell describes the relevant problem as follows:

The word 'this' is one word, which has, in some sense, a constant meaning. But if we treat it as a mere name, it cannot have in any sense a constant meaning, for a name means merely what it designates, and the designatum of 'this' is continually changing. If, on the other hand, we treat 'this' as a concealed description, e.g., 'the object of attention', it will then always apply to everything that is ever a 'this', whereas in fact it never applies to more than one thing at a time. Any attempt to 114).

${ }^{4}$ This point is only stated here. For a persuasive defense of it, cf. (Roberts 1984: 113-

${ }^{5}$ Although (PA) may be read as a principle of word-understanding, I invoke it here to ground a principle of meaning rather than one of understanding. 
avoid this undesired generality will involve a surreptitious reintroduction of 'this' into the definiens. (Russell 1962, 103; and cf 1956b, 201) ${ }^{6}$

While the use of indexicals shows certain commonalities with that of names', ${ }^{7}$ the former also varies from the latter in significant ways. In each occasion of use, the meaning of names and indexicals is similarly determined: one may understand what those terms mean by becoming acquainted with the items they pick out. However, while names typically pick out the same objects across different contexts, indexicals pick up on different objects over different occasions of use. The problem thus seems to be that, vis-à-vis (PA) and the way names are usually used, indexicals misbehave. Against this backdrop, Russell raises two further related questions: (a) what indexical terms mean; and (b), why their usage differs from that of other grammatical categories, such as names and descriptions. In the next section, I outline the answers Russell apparently provided for (a) and (b).

\section{INDEXICALS AND DEICTIC MACHINES}

To the extent that he takes it to be fundamental among indexical expressions, Russell pays special attention to the term 'this'. It is unclear to me in what precise sense that expression-as opposed to, say, 'I'-is supposed to be fundamental, or again, what the exact implications of that fundamentality claim are. But there is strong textual evidence suggesting that Russell wanted reductively to analyze other indexical expressions in terms of 'this' (cf. Russell 1962,102), a move that seems problematic, to say the least. To dodge this complication, I shall read Russell's claim as a minimal methodological thesis to the effect that 'this' is fundamental in the following sense: by focusing the discussion on one representative indexical term-namely, 'this'-Russell devotes his attention to analyzing a paradigmatic sample of a whole linguistic category instead of discussing indexical expression by indexical expression; and, in doing so, he fleshes out an account that, if plausible, could then be extrapolated to our understanding of other indexical terms.

${ }^{6}$ Bearing Kaplan's distinction between content and character in mind, one could argue that indexicals do have a constant meaning-i.e. character-across different contexts: only their contents change (cf. Kaplan 1989). Since the distinction is quite specific to Kaplan's work, however, I believe it would be unfair to extrapolate it to a critical assessment of Russell's remarks: as such, the above claims about meaning are best read as concerning a general notion of meaning that embraces both content and character.

7 'The word 'this' appears to have the character of an ordinary name, in the sense that it merely designates an object without in any degree describing it.' (Russell 1962, 103) 
To unpack his account of 'this', Russell resorts to the following thought experiment. Consider a machine capable of making a rudimentary but accurate use of indexical expressions. This machine should be competent enough to use words 'this' and 'that': that is, it should, among other things, be capable of using those terms in the way any ordinary human adult would correctly use them. A special feature of these words is that a given utterance of 'this' and of 'that' may refer to one and the same worldly item. In the present thought experiment, Russell supposes that the aforementioned machine uses both words to refer to one and the same object-let's say, a cat. ${ }^{8}$ In relation to the present example, it is relatively clear how Russell would partially answer (a), the question what an indexical term means: (PA) seems to ensure that a particular cat determines the meaning of the uttered expressions. But this it is not the whole answer to (a), for Russell does not wholly rely on (PA) alone in order to account for indexicals: regarding these special expressions, he thinks that their meaning is not only fixed by what they refer to, but also by the way in which they do so. In other words, Russell limits the scope of (PA) as a criterion of meaning for indexicals, a thought on which I expand next.

Russell uses an example like the one I previously introduced in order to address three further points: (i) what would have to take place inside the relevant machine so as to result in the linguistic utterance 'this is a cat'; (ii) what would have to take place inside it so as to result in the linguistic utterance 'that is a cat'; and (iii), how the differences between both internal processes could throw light on the ways in which 'this' and 'that' are used. Russell thinks that the relevant machine simplifies and thereby illustrates the sort of cognitive causal mechanism that human beings could also implement (cf. Russell 1962, 105): as such, while crude, a deictic machine is intended to clarify the complex ways in which we use indexicals. ${ }^{9}$ Let's turn to what he says about (i)-(iii).

According to Russell, the machine's use of demonstratives is underpinned by causally related phenomena (cf. Russell 1962,105). To the extent

8 Throughout this piece, I assume that terms refer to ordinary worldly objects. In Russellian semantics, however, this point is not quite so simple: after all, a prominent epistemological theme in Russell's epistemology is his apparent allegiance to sensa or sensedata. I am inclined to think that the terminology of sense-data does not necessarily commit Russell-or, for that matter, other alleged sense-datum theorists, such as Moore and Ayerto a belief in the existence of private, mental objects of awareness. (For a more nuanced understanding of such a terminology, cf. Ayer 1945,1973.) That said, Russell's theory of perception is far too complex and delicate for proper discussion in the present piece.

9 This simplifying approach is by no means fantastic: cognitive scientists frequently resort to it in what are nowadays known as models of minimal cognition (cf. Beer 1997, 2003; Di Paolo, Buhrmann, and Barandarian 2017, ch. 3). 
that his goal is to address conceptual rather than operational or technical issues, he keeps his description of the relevant causal processes fairly general (cf. Russell 1962, 106). Russell takes it for granted that 'this' and 'that' intuitively refer to material particulars. However, this fact does not account for indexicals' misbehavior on its own. To account for the latter, he compares the use of the words 'this' and 'that' so as to find out what characterizes the use of each term. As the previously quoted passage suggests, the main difference between 'this' and 'that' would have to do with variations alongside the causal chains that bridge the stimulus-that is, what we refer to-and the response-that is, the utterance of an indexical-underpinning the relevant deictic identifications: while uttering 'this' is explained as the outcome of the shortest-or minimal, in Russell's words-causal chain between the indexical terms and the referred object; uttering 'that' is in turn the outcome of a longer causal chain. The relative complexity of the underpinning causal chains thus become crucial for drawing the distinction between 'this' and 'that':

A minimal causal chain, in this connexion, is the shortest possible chain from a stimulus outside the brain to a verbal response. Other causal chains always involve some additional stimulus, causing the stored effect of the previous stimulus to be released and to produce a delayed verbal response. In the case of a minimal causal chain we say 'this is', and in the case of a longer one we say 'that was'. (Russell 1962, 105)

The explanatory relevance of minimal causal chains may seem dubious insofar as they might fail to distinguish 'this' from a grammatical category like that of names: although the utterance of names also results from a very short causal chain between an object in the speaker's surroundings and the verbal utterance, names do not misbehave vis-à-vis (PA) the way indexicals do. Hence, the previous thought experiment would not solve the initial problem of distinguishing the use of 'this' from that of other expressions. Ultimately, this difficulty seems to derive from the more general worry that the notion of a causal chain is somewhat imprecise (cf. Roberts 1984, 115).

Russell's account provides the basic elements to meet the previous challenge, though. A distinction between indexicals and names may be drawn by specifying the notion of a causal chain a bit further. The above quote suggests that the relative length of a causal chain would be determined in accordance with a temporal criterion: that is, a causal chain A would be longer than a causal chain $B$ iff $A$ was extended over an interval of time, $t_{A}$, longer than the interval of time, $t_{B}$, over which $B$ is extended. Hence, a minimal causal chain would be the temporally shortest one between its relata-again, the relata being the referred object, on the one hand, and, on 
the other, the utterance of the referring linguistic expression. But, in addition to this temporal criterion, I believe one could expand on Russell's suggestion by claiming that the relative length of causal chains could also be determined, say, by the relative amount of cognitive resources devoted to implement the causal chains at stake. For example, one could argue that, even if two instances of a causal interaction between world and linguistic act involve the same temporal duration, one of such causal processes might demand a relatively smaller amount of cognitive resources than the other one-perhaps because the latter cognitive process involves the actualization of further resources from the language-user's conceptual repertoire. In short, the present point is that the relative length of Russell's aforementioned causal chains may be determined by different elements: not only temporal ones, as he says; but also by cognitive or conceptual ones.

If plausible, the previous remarks suggest that a speaker's use of names and that of indexicals do differ in accordance with differences in their underpinning reference-utterance causal chains. Of course, whether the demonstrative use of indexical terms doe indeed demand fewer cognitive resources than the use of other linguistic terms, is an empirical question. In principle, it does not seem implausible. Research on early development of language, for instance, shows that children tend to master a context-bound use of words - such as indexicals-before mastering that of referential, noncontext-bound words (cf. Barrett 1995, 364-375). On the plausible assumption that this order of development is correlated with the progressive sophistication of children's cognitive processes, then the hypothesis that the deictic use of indexical terms involves shorter causal chains, in the sense above explained, turns out to be quite suggestive.

By comparing 'this' and 'that', Russell identifies the distinguishing feature of a machine's usage of the term 'this': 'the difference between a sentence beginning 'this is' and one beginning 'that was' lies not in their meaning, but in their causation.' (Russell 1962,106) The peculiarity thus emerging not only reveals differences between the way speakers use 'this' and 'that', but also differences between the ways in which they use 'this' and ordinary names in general. Indexicals would not stand out for referring to a peculiar category of items: they refer to the same kind of worldly items as names. What distinguishes the deictic use of indexicals is the peculiar kind of causal chains underlying the verbal utterances of indexicals. Among indexical terms themselves, Russell highlights the use of 'this' and 'that' for the relatively minimal length of their underpinning causal chains: the verbal utterance of 'this' is a more or less direct result of perceptual stimulus; the 
verbal utterance of 'that', in turn, is the result of perceptual stimulus, via intermediate-perhaps short-term-memory links (cf. Russell 1962, 106). Compared to the referential use of names, the deictic use of indexicals involves temporally or cognitively shorter causal chains. Thus, indexicals like 'this' and 'that' will refer to the same kind of material object as a name like 'cat': however, vis-à-vis the causal relationships underpinning the utterance of other kinds of linguistic expressions, the use of indexicals involves shorter causal chains. As a result of this, Russell's understanding of indexicals seems to be one according to which their meaning is not only fixed by what they refer to-as suggested by (PA) - but also by the way in which they do so.

Russell's reply to (a) and (b) thus runs as follows. Regarding (a), the meaning of indexical terms used in a deictic way is partly constituted by those items these expressions pick up on. Regarding (b), indexical-usage differs from name-usage and description-usage because indexicals pick up on worldly items in ways causally different from those in which names and descriptions do so. This answer to (b) complements that to (a): the meaning of indexical terms is fixed not only by their respective referents, but also by how the relevant terms and the referred items are causally related. If this suggestion is along the right lines, Russell's treatment of indexicals would in turn circumscribe the scope of (PA). Indeed, he concedes that the meaning of an expression is partially governed by that principle. But then, he also makes room for another element to determine the meaning of indexicals, namely, the way in which such an expression picks its referent out. This alternative reading of Russell's indexicals does not undermine his well-known reliance on (PA): it only tells us that the latter principle does not give us the whole story about how indexicals are used.

To finish off, let's go back to the question whether Russell's account of indexicals may be applied to expressions other than 'this'-e.g. 'I', 'here', 'now', etc. I previously mentioned that Russell depicts 'this' as a more fundamental kind of indexical than other terms. I suggested that this claim could be understood in two ways: on the one hand, as a serious attempt to reduce indexicals into 'this'; and, on the other, as a methodological move by means of which he aims to focus on one sample, so as to develop an account that could then be applied to other indexical expressions. To support the latter reading of Russell's intentions, one could sketch how this extrapolation might go. Consider the first-person pronoun in the context of an example such as those used by John Perry to describe the problem of essential indexicals (cf. Perry 1979). More specifically, I shall revisit the relatively neglected story of Winnie-the-Pooh's hunt for the enigmatic Woozle (cf. Milne 2001). Unbeknown to Pooh, he and Piglet were after all following their own tracks 
in a circle. That said, Pooh was (to some extent) justified in believing that the tracks belonged to a sneaky creature, without believing that he was that sneaky creature. Why? Based on Russell's account of indexicals, one could say that, although 'a sneaky creature' and 'I' pick up on the same item-that is, Pooh himself-they mean different things because the meaning of a linguistic expression is partly determined by the way such an expression is causally connected to that object: 'a sneaky creature' picks out Pooh in what Russell would call a causally indirect way, while 'I' picks him out by means of a relatively shorter causal chain. Similar explanations could, I believe, be developed for other indexical terms.

To sum up, Russell's initial problem was this: indexicals in some sense seem to have a constant meaning; however, they cannot be categorized either as names or as definite descriptions-at least not in a way neatly governed by (PA). The goal was then to provide an account of indexicals that preserved their apparent semantic consistency-or, to put it in a different way, their resemblance to ordinary names-and, at the same time, their peculiar context-sensitive referential shifts. Russell solves the problem by understanding 'this' as the outcome of a minimal causal chain between a referred object and the utterance of the corresponding referring expression. 'This' refers to worldly items in a way which is similar to that in which names do so: both 'this' and a name like 'cat' would result from causal chains between the referred object and the relevant verbal utterances. Unlike names, though, 'this' refers to a different object on each different occasion of use because its meaning also depends on how the term is causally linked to the object it refers to.

\section{A WORLD WITHOUT INDEXICALS?}

Even if the present reading of Russell's account of indexicals is convincing, there still remains his damning conclusion that such terms 'are not needed in any part of the description of the world, whether physical or psychological'. What does this amount to if not an attempt of dispensing with indexicals? I shall briefly address this claim.

According to Russell, scientific disciplines like physics and psychology aim to develop an objective representation of reality: that is, a representation the expression and the contents of which do not depend on a subject's vantage point. Indexicals are unnecessary in that representation precisely because they represent reality in a subjective manner: they are perspectival insofar as what they refer to is fundamentally bound to the circumstances in 
which the relevant expressions are used. ${ }^{10}$ As such, a tension between the usage of indexicals and an objective representation of the world emerges: the kind of subjectivity that the language of physics and scientific psychology aims to avoid is precisely the kind of perspectival subjectivity involved in indexical expressions (cf. Russell 1962, 102-103). But what conclusion does Russell draw from this tension? Not, I believe, that natural languages could in principle dispense with indexicals. By means of that contrast, he highlights the subjective or perspectival character of indexicals. While this feature is incompatible with a fully objective representation of the world, natural languages are not supposed to be perspectiveless. Indeed, on the plausible assumption that one of its primary aims is to enable communication among individuals constrained by temporal or spatial limitations-and, as such, circumscribed to a particular vantage point in the spatio-temporal world-language seems bound to be perspectival. For sure, the ideal of an objective representation of the world may be useful in certain contexts-for example, when it comes to outline the goal of intellectual enterprises like the natural sciences. But, as long as language remains perspectival, its incorporation of perspectival expressions is not optional. Hence, although it may be tempting to read Russell's remarks as suggesting that we could in principle dispense with indexicals, he only seems to highlight the fundamentally perspectival character of such expressions: and while that feature perhaps has no room in an objective picture of the world, it is-not only in practice, but also by principle-part and parcel of the linguistic representations used by finite subjects like us.

The previous contrast is also relevant for another reason. Russell not only tries to convey the distinctively perspectival dimension of indexicals by means of causal chains that more or less fit stimulus-response psychology: he tries to do so without invoking mysterious or otherwise special entities. As previously explained, Russell accounts for the idiosyncratic behavior of indexicals in terms of the ways in which such expressions are used, not in terms of the items they refer to. Our world-view - that is, our general understanding of the objective world-only includes items such as those described in scientific disciplines like physics and psychology: they exhaust the realm of things the different expressions in our natural languages could refer to. In short, what there is, is only what natural sciences reveal to us. The existence of misbehaved linguistic terms like indexicals do not, in turn, suggest that there is anything else beyond that realm. Whether successful or

${ }^{10}$ For an understanding of subjectivity in terms of perspectival representation and, correspondingly, one of objectivity in terms of non-perspectival representation, cf. (Eilan 1997, 239). 
not, Russell's account is naturalist in spirit not only because it seeks to accommodate the peculiar usage of indexicals in terms of the aforementioned causal story, but also because it does so without committing to the existence of special referents, e.g. introspectively accessible Cartesian selves. So, in this sense, indexicals do not refer to anything special in an objective representation of the world: accordingly, they are not necessary for a full picture of that world-view. In another sense, however, indexicals are absolutely necessary. As previously explained, natural languages like ours do not exist in a purely objective world: as long as one of their primary purposes consists in opening up the world to finite beings, they are bound to remain subjective or perspectival. On the plausible assumption that indexicals help reflecting the perspectival dimension of language in general, they will also constitute a non-redundant part of those linguistic representations formed from a particular vantage point. For Russell, then, indexicals could not be eliminated from natural languages.

\section{CONCLUSION}

To sum up, the Russellian account of the deictic use of indexical expressions does not aim to challenge our ordinary and legitimate use of indexicals. As stressed by the Misbehavior Problem, indexicals express things we do commonly express by means of names and descriptions: however, they pick up on different items from context to context. According to Russell, indexicals misbehave because their referents are defined by minimal causal chains between referred items and referring utterances. This causal account thus acknowledges the peculiar ways in which indexical expressions are used, and, perhaps more generally, the way in which indexicals are context-sensitive. At the same time, such an account is naturalist in spirit insofar as it avoids invoking special items in order to accommodate the peculiar behavior of indexicals.

Against that backdrop, I addressed the question whether Russell takes indexicals to be in principle eliminable from natural languages. I believe that he does not: as far as I can see, all he does is to acknowledge the perspectival character of indexical-usage. For sure, my supporting remarks by no means constitute a full-fledged defense of Russell's account of indexicals. For example, the claim that such expressions constitute the outcome of minimal causal chains ultimately stands in need of psychological and neurolinguistic verification. Again, the possibility of adapting Russell's account to indexical terms other than 'this' must be further explored. Finally, there are a number of difficulties related to the role played by perception and attention in the 
ways we use indexicals (cf. Roberts 1984, 115-116). None of the emerging obstacles, however, seem a priori damning: as far as I can see, they simply hint at some of the challenges that, like any other philosophical proposal, a Russellian account of indexicals would have to overcome. For the time being, I have only strived to undermine a fundamental and yet unfair charge against an otherwise stimulating aspect of Russell's philosophy of language. 


\section{BIBLIOGRAFIA}

Ayer, Alfred. 1945. “The Terminology of Sense-Data.” Mind 54: 289-312.

- - 1973. The Central Questions of Philosophy. London: Weidenfeld and Nicolson.

Barrett, Martyn. 1995. "Early Lexical Development." In Paul Fletcher and Brian MacWhinney (eds.), The Handbook of Child Language. Oxford: Blackwell: 362-392.

Beer, Randall. 1997. "The Dynamics of Adaptive Behavior: A Research Program." Robotics and Autonomous Systems 20: 257-289. https://doi.org/10.1016/S0921-8890(96)00063-2.

- - 2003. "The Dynamics of Active Categorical Perception in an Evolved Model Agent." Adaptive Behaviour 11: 209-243.

https://doi.org/10.1016/j.neunet.2009.03.002.

Bostock, David. 2012. Russell's Logical Atomism. Oxford: Oxford University Press.

https://doi.org/10.1093/acprof:oso/9780199651443.001.0001.

Di Paolo, Ezequiel, Buhrmann, Thomas \& Barandarian, Xabier. 2017. Sensorimotor Life: An Enactive Proposal. Oxford: Oxford University Press. https://doi.org/10.1093/acprof:oso/9780198786849.001.0001.

Eilan, Naomi. 1997. "Objectivity and the Perspective of Consciousness." European Journal of Philosophy 5: 235-250.

https://doi.org/10.1111/1468-0378.00038.

Kaplan, David. 1989. “Demonstratives.” In Joseph Almog, John Perry, and Howard Wettstein (eds.), Themes from Kaplan. New York: Oxford University Press: 481-614.

Martin, M. G. F. 2015. "Old Acquaintance: Russell, Memory and Problems with Acquaintance." Analytic Philosophy 56 (1): 1-44. https://doi.org/10.1111/phib.12059.

Milne, A.A. 2001. "Winnie-the-Pooh." In Winnie-the-Pooh: The Complete Collection of Stories and Poems. London: Egmont: 36-41.

Perry, John. 1979. "The Problem of the Essential Indexical." Noûs 3-21. https://doi.org/10.2307/2214792.

Roberts, Lawrence. 1984. "Russell on the Semantics and Pragmatics of Indexicals." Philosophia 14: 111-127. https://doi.org/10.1007/BF02378963.

Russell, Bertrand. 1918. "Knowledge by Acquaintance and Knowledge by Description." In Mysticism and Logic, 209-32. New York: Longmans, Green \& Co.

- - - 1956a. "On the Nature of Acquaintance." In Logic and Knowledge, 127-74. London: George Allen \& Unwin. 
- — - 1956b. "The Philosophy of Logical Atomism." In Logic and Knowledge, 175-281. London: George Allen \& Unwin.

_-_. 1962. An Inquiry into Meaning and Truth. Harmondsworth: Pelican Books.

Sainsbury, Mark. 1979. Russell. London: Routledge \& Kegan Paul.

Soles, Deborah. 1981. "Russell's Causal Theory of Meaning." Russell 1: 27-37. https://doi.org/10.15173/russell.v1i1.1522. 